\title{
A Note on Conventions
}

There is no standard orthography to represent Maring speech, and each ethnographer has tended to develop his or her own system. This variability partly reflects dialect differences: Maring put some importance on sometimes minor variations in pronunciation and vocabulary in different dialects. The orthography I have chosen is only broadly phonetic; I have tried to render Maring words readable rather than indicate precisely how they sound. Letters used have the same values as in Tok Pisin (Neo-Melanesian Pidgin), with the exception that the letter $c$ indicates the $c h$ sound in English "church." The letters $n g$ sound as in "sing" and ngg as in "finger." The greatest liberty I have taken is with the use of the schwa, the short, unrounded vowel as in the first vowel of the British pronunciation of "banana," for which no romanized symbol suffices. In some words I have simply omitted this vowel, as in ambra ("woman") where it occurs between $b$ and $r$; in others I have rendered it with a vowel that most closely approximates its sound in context, as in both vowels of the personal name Menek, or the last vowel of yimunt ("tree fern").

Tok Pisin words and phrases are indicated by the letters TP in parentheses.

Bird and other animal names present some problem. There are few standardized English vernacular names, and many are cumbersome (e.g., Yellow-billed Mountain Lory). Scientific names may be more acceptable to specialists but are even less comprehensible to the general 
reader (e.g., the parrot just mentioned is known to ornithologists as Neopsittacus muschenbroekii). Although I feel that precise identifications are important, I mostly refer to birds (and some other animals) by English vernaculars, the more cumbersome ones sometimes shortened. Precise identifications are listed in appendix 2.

The Maring have known three currencies: Australian pounds (to 1965) and dollars, and national Kina (K) since Independence in 1975. All monetary values are expressed in Kina (though most valuations occurred before 1975), with no adjustment for revaluations, at the rate of 10 shillings to $\$ A 1$ to K1. There are 100 Toea to the Kina. The Kina was at parity with the Australian dollar, though revaluations now place it at about \$A1.50. To avoid confusion with the marine shell known in Tok Pisin by the same name (and after which the currency is named), the shell (also known as pearlshell) is referred to with a lower case " $k$," the currency with a capital "K." 